\title{
Undergraduate Students' Perspectives of the Extent of Practicing Netiquettes in a Jordanian Southern University
}

\author{
https://doi.org/10.3991/ijet.v12i03.6424 \\ Y. M. Arouri \\ Tafila Technical University, Tafial, Jordan \\ yousef@nmsu.edu \\ D. A. Hamaidi \\ The University of Jordan, Amman, Jordan \\ dhamaidi@ju.edu.jo
}

\begin{abstract}
The study aimed at investigating the extent of implementing Netiquette practices among University students at Tafila Technical University (TTU). The study included the students of Faculty of Educational Sciences at TTU- Jordan, who enrolled in fall semester of the academic year 2015/2016. To achieve the aim of the research study, researchers used the descriptive research method. A quantitative questionnaire, consisted of (42) items was developed and administered on (245) male and female students of special education and classroom teacher majors. The findings of the study revealed that the university students have a consensus regarding the general rules of Netiquette. However, they pointed out limited awareness of specific Netiquette rules and aspects. As a result, their practices reflected varied levels of implementation. In addition, the results revealed that the students' perspectives of the implemented Netiquette practices were not affected by gender, specialization, or university study level. Furthermore, the implemented practices revealed that the students' perspectives show limited extent of Netiquette practices related to critical thinking skills. Further implications and future recommendations were discussed.
\end{abstract}

Keywords-Netiquette Practices, Undergraduate Students, Students' Perspectives, Jordanian Universities

\section{$1 \quad$ Introduction}

Acquiring advanced communication skills is a vital attribute of the $21^{\text {st }}$ century people around the world since knowledge could not be existed without communications and interactions. Communication skills have several formats that include verbal and written language, gestures, symbols, and colors. The major communication tool among people takes place through face-to-face in order to express and deliver meanings and ideas directly to others. However, the new digital technologies have changed the way of how individuals communicate and force them to create a new arena of 
interactions. According to Biesenbach-Lucas [4] to perform effective and safe communication with others, individuals should possess adequate interaction skills. Therefore, in order to hold an effective and safe online communication, online users should learn, understand, and then practice the rules of Netiquette.

The term Netiquette is formed by combining two words: networks and etiquette [31]. However, Aggarwal [1] addressed that the term of Netiquette includes two factors: the Internet and etiquette. According to Merriam-Webster's Learning Dictionary [27] etiquette means the "rules indicating the proper and polite way to behave" (n.a.), while the Internet means "a system that connects computers throughout the world" $[28$, n.a.].

Given previous knowledge, Netiquette is considered as an "electronic etiquette" [7, p. 279] or "ethics of digital communication" [1, p. 181] that means "appropriate behavioral etiquette when communicating through computer networks or virtual space" $[37$, p. 1]. In other words, Netiquette is "the rules for the proper and appropriate way to communicate using electronic devices or activities online" [7, p. 279]. With the same sense, Scheuermann and Taylor [32] and Aranda [3] considered Netiquette as etiquette or rules that should be followed to foster online communication. In brief, Netiquette derived from two concepts: etiquette and the Internet, which refers to the set of ethical rules, politeness, conventions, and etiquette standards that should be learned, understood, and practiced by users communicating and utilizing electronic devices, tools, and applications.

Currently, Netiquette practices are also crucial for university students since the Internet users are increasing rapidly around the world. Those results indicated that the Internet spreads rapidly worldwide. However, the Internet attracts arrival of millions of individuals who are completely unready and unprepared to experience the complex dynamics of online communication. This situation gradually made it necessary to consider the rules.

According to West [36] there are many university students struggle with utilizing online tools and applications in their formal online courses. West demonstrated that most of students use applications such as Facebook, MySpace, Yahoo, and Google groups. However, university students have a lack of familiarity with practicing online ethical rules during sharing cooperation tools for learning in their online learning environment. With same sense, Deepa and Ghatak [11] pointed out that a huge quantity of electronic messages, which online individuals sent between each other, could be misunderstood in content as well as tone. This situation would lead to a negative interaction process. So, the need for implementing Netiquette practices is a vital demand to enhance the quality of online interaction process.

Given previous discussion indicated that there is a lack of Netiquette implementation among students. Therefore, realizing the significance of Netiquette is necessary but not sufficient, because building online ethical rules requires sustainable effort. With different options available in online environments, the Internet users should invest their efforts to use rules of Netiquette, and support other users while they are experiencing online ethical rules. According to West [36] the main factor, that affects individuals' interaction, is understanding the rules of online communication (Netiquette). Practicing Netiquette rules will help users build stronger online interaction 
community [9;23]. In addition, it leads users to a more reflective discourse [16]. Moreover, it makes users feel more connected, engaged, motivated and involved and more respectful for users' diversity [35; 29].

Consequently, ignoring the practices of Netiquette would lead the Internet users to flaming and feeling isolated, unconnected, unmotivated, and uninvolved in online interaction community. Therefore, Netiquette should be incorporated as a part of undergraduate and graduate programs at university levels [21].

As a result, this study attempts to investigate the level of implementing Netiquette practices among undergraduate students at one of the southern universities in Jordan. Specifically, the study focuses on the extent of Netiquette practices among TTU students at the Faculty of Educational Sciences.

\section{$2 \quad$ Research Problem and Questions}

Previous Literature $[15 ; 17 ; 25 ; 33 ; 31 ; 10 ; 19 ; 34 ; 18 ; 22 ; 24 ; 36]$ focused on the importance of rules of online communication (Netiquette) that online users should possess during the communication. However, several studies [26; 1123] indicated that there is a lack of understanding and practicing the rules of Netiquette among students. Based on their experiences as faculty members, the researchers in this study noticed that undergraduate students have a lack in the understanding and implementation of the rules of Netiquette.

This study attempts to learn more about undergraduate students' perspectives of the extent of Netiquette practices. In addition, the study aimed at exploring the effects of some variables such as gender, specialization, and level of study-year on students' Netiquette practices. In particular, this study tries to answer the following questions:

1. To what extent do undergraduate students, at the Faculty of Educational Sciences at TTU practice Netiquette?

2. Are there statistically significant differences at the significance level of $(\alpha=0.05)$ between means responses of undergraduate students regarding practicing Netiquette rules attributed to the students' gender?

3. Are there statistically significant differences at the significance level of $(\alpha=0.05)$ between means responses of undergraduate students regarding practicing Netiquette rules attributed to the students' specialization?

4. Are there statistically significant differences at the significance level of $(\alpha=0.05)$ between means responses of undergraduate students regarding practicing Netiquette rules attributed to the students' university study level?

\section{Research Importance}

The significance of this study emerges from the importance of Netiquette impact and its role in enhancing university students' level of effective communication skills online. Furthermore, this study attempts to play a role in strengthening online ethical rules that requires sustainable effort. In addition, this study is vital because it consid- 
ers the perspectives of university student who are directly affected by the Netiquette quality and the nature of online communication environments. Furthermore, the results of this study may draw attention to Netiquette concept and its aspects and rules to increase awareness of this new concept and its effects. Therefore, this study attempts to present the specific meaning of Netiquette and its related practices that may help educational stakeholders to disseminate the practices at university level.

\section{Terms And Procedural Definitions}

Degree of practicing Netiquette: It is the degree of implementing Netiquette rules among students of the Faculty of Educational Sciences at TTU while accessing online communications. In this research study, the extent will be measured based on the degree obtained by the participants on the study instrument.

Undergraduate students: The students of the Faculty of Educational Sciences at TTU who are completed (66) credits from their study plan.

Netiquette: "the rules for the proper and appropriate way to communicate using electronic devices or activities online" [7]. In this research study, the term Netiquette refers to the set of items that formed the study instrument. It consisted of (42) items that cover the aspects of Netiquette.

\section{$5 \quad$ Limitations}

The study was administered solely on undergraduate students of special education and classroom teacher specialization from the Faculty of Educational Sciences at TTU. The study was conducted in the fall semester of the academic year 2015/2016. Generalization of the study findings is limited based on the instruments used to collect data and its psychometric properties of reliability and validity.

\section{Research Variables}

This research study has three independent variables and one dependent variable. The independent variables are: 1) gender of the students which has two levels: Male and Female, 2) specialization of the students which has two levels: classroom teacher, and special education majors, 3) level of study-year which has two levels: first, undergraduate students who are completed (66) credits from their study plan (the thirdyear of undergraduate study program), and second the students who are completed (100) credits from their study plan (the fourth-year of undergraduate study program). The dependent variable is the extent of Netiquette practices implementation. 


\section{$7 \quad$ Literature Review}

By reviewing previous research in the topic of Netiquettes many aspects were featured. The first aspect covers familiarity with Netiquette rules. In this regard, Farshad and Marandi [12] conducted a comparative study to explore the degree to which 75 English as foreign language (EFL) learners and their 53 native English counterparts were familiar with Netiquette rules and perceived them as useful. The results of the study indicated that EFL learners were not familiar enough with the Netiquette rules, and they did not realize the usefulness and necessity of Netiquette rules comparing with the native English learners. In addition, the results focused on the importance of preparing students of 21 st century to get acquainted with the Netiquette rules.

In their research study, Kozík and Slivová [21] discussed the contribution of Netiquette in higher education institutions. The sample of the study was a group of employers and graduates of engineering study programs at eight universities in Slovak. Researchers concluded that: 1) Netiquette should be incorporated in higher education programs at the universities. The rules should be considered at undergraduate programs as well, 2) Netiquette should be educated in the form of elective seminar courses, 3) it is recommended that students who graduate from these courses should gain a certificate.

Deepa and Ghatak [11] conducted a quantitative exploratory study that aimed at finding the perception about using most agreed upon Netiquette practices while writing a professional email. This research used primary data that was collected by utilizing an online questionnaire. The size of sample was 500 professionals throughout India who use e-mails mostly for any kind of communication. The findings revealed that academic institutions should "organize workshops and training sessions for the sensitization of using correct procedure in email communication" [11, p. 129]. These trainings on institutional level can guide students to use email appropriately and prepare them to transfer this learning to other aspects in their life.

Bromseth's [6] study illustrated the type of the Internet-mediated discussion, and the processes that create discussion culture on the Web. In other words, the researcher examined how the existing discourse of Netiquette forms a basis for the two Norwegian discussion negotiation processes. Researcher used several cases from two Norwegian email-based mailing lists. It was argued that "the interactional norms that get a hegemonic position in a certain context result from socially and culturally situated negotiation processes" (p. 80). These processes are linked to gender and culture. The finding pointed out that there is an impact of a specific culture on Web discussion.

The other aspect of literature review covered rules of Netiquette in using blogging, email, and other online communication practices. Aggarwal [1] conducted a study that took place at an urban public university in the Mid-Atlantic area. The participants were two groups of students studying two MBA courses, one introductory and another elective course. Both courses are online and have diverse student populations in terms of gender, race, and nationality. This research study attempted to develop Netiquette for a specific group (E-Learning) of students. It distributed a questionnaire to get student's responses regarding their perceptions of communication. The findings showed that students perceive what instructors write in the forum is of most im- 
portance. The researcher concluded that users communicate via social media should be guided to follow and understand standards of electronic communication or Netiquette to keep each person civil and safe.

In her research study, Aranda [3] addressed numerous issues related to Netiquette. First, how Netiquette is learned and the effect the learning method has on its application. Second, the implications of particular rules of Netiquette in cross-cultural communication. Third, the importance of modifying rules of online communication based on the evolution of technology. Finally, the general guidelines for proper Netiquette. The results indicated that any online community should create, follow, and disseminate the acceptable norms of communication. Further, instructors should play their role in guiding students to practice online communication rules. Furthermore, Users of online communications should learn appropriate communication rules, and teach and aid new users to practice them.

Buelens et al. [8] demonstrated that it is already known and there is evidence that instructive guidelines improve the quality of asynchronous discussion in education. The study used an experimental method. The sample of the study included 112 students graduating in the biomedical sciences, and it was randomly selected from electronic discussion groups of 18-19 participants each. Findings of this study indicated that "providing Netiquette guidelines alone did not improve the quality of discussions. However, supplying Netiquette in combination with didactic guidelines was effective" [8, p. 712). That is informative guidelines and rules on the implementation of Netiquette can help the participants in each discussion groups to understand the expected roles. So, they will provide appropriate reactions.

As a conclusion, all of the previous literature discussed in this research addressed the issues related to Netiquette and online communication. Some research studies such as Kozík and Slivová [21] and Deepa and Ghatak [11] focused on the importance of email etiquette rules (Netiquette) that should be utilized by users. In addition, these studies addressed several rules (do's and don'ts) for email Netiquette in order to assist users to apply email more effectively. Other research studies such as Farshad and Marandi [12], Aggarwal [1], and Bromseth [6] investigated the perceptions toward Netiquettes and the effects of practicing Netiquette in electronic communication systems such as blogs, forums, and social media applications on facilitating intercultural communication and reduce distance and misunderstandings among users. However, there is paucity in studies that investigate Netiquette and its effects on undergraduate students who use electronic communication systems. As a result, this research aims to investigate the extent of Netiquette practices from both classroom teachers and special education undergraduate students' perspectives at TTU. It attempted to add to the previous literature by highlighting the implemented Netiquette practices of undergraduate students and the effect of some variables on the level of Netiquette implementation. 


\section{$8 \quad$ Research Methodology}

To answer research questions, the researchers used the descriptive research approach which is objective and it describes the reality from the participants' own perspectives. According to Jong and van der Voordt [20] descriptive research should be "restricted to factual registration and that there is no quest for an explanation why reality is showing itself this way" (p. 53). This type of approaches doesn't include just gathering the data but also includes analyzing, organizing the data collection [14]. Given previous leaded the researchers to use the descriptive approach by developing a questionnaire and distributing it to the research participants.

\subsection{Research Population and Sample}

The research sample and research population were the same due to limited number of students enrolled at Faculty of Educational Sciences/TTU- Jordan. Therefore, the research sample included all undergraduate students (267) at the Faculty of Educational Sciences who registered for the fall semester in the academic year of 2015/2016 based on the records of the Unit of Admission and Registration. The participants completed (66) credit hours from their study plan in the specializations of classroom teacher and special education. Researchers, based on the study plan, considered the students who completed (66) credits from their study plan in the third-year undergraduate-level study, and the students who completed (100) credits from their study plan in the fourth-year undergraduate-level study.

\subsection{Data Collection}

Research data were generated in quantitative form and collected from the students who completed (66) credits from their study plan. A total of (22) students were invited to participate in this study for the purposes of research validity and reliability. Therefore, a total of (245) surveys were distributed during the fall semester of the academic year 2015/2016 to collect the research data. The participants were introduced to the purpose of the research, and invited to read and sign the survey consent form that included information about research objectives, and the benefits and risks of participating in this research.

Among the 245 respondents, 105 (42.8\%) of them were male students whereas $140(57.1 \%)$ were female students. According to participants' specialization, there were $125(51 \%)$ students of classroom teachers major and (120) $(49 \%)$ students of special education major. In terms of level of study-Year, there were $115(47 \%)$ students in the level of third-year study whereas $130(53 \%)$ students were in the level of fourth-year study. Table 1. demonstrated the sample of the study according to the study variables. 
Table 1. Study Sample Distributed According To Study Variables: Gender, Specialization, And Level Of Study-Year

\begin{tabular}{|l|c|c|c|c|c|}
\hline \multirow{2}{*}{ Specialization } & \multicolumn{2}{|c|}{ Third-Year Study } & \multicolumn{2}{c|}{ Fourth-Year Study } & \multirow{2}{*}{ Total } \\
\cline { 2 - 5 } & Male & Female & Male & Female & \\
\hline Classroom Teacher & 25 & 35 & 25 & 40 & 125 \\
\hline Special Education & 25 & 30 & 30 & 35 & 120 \\
\hline Total & 50 & 65 & 55 & 75 & 245 \\
\hline
\end{tabular}

\subsection{Research Instrument}

Developing a research instrument required an intensive review of related literature $[15 ; 13 ; 17 ; 33 ; 34 ; 18 ; 2 ; 22 ; 24 ; 36 ; 21 ; 5 ; 29]$. Research instrument consisted of two sections. First is demographic information that included gender, specialization, and level of study-year. The second section is a quantitative questionnaire included (42) items. The study participants responses on the questionnaire items was according to Likert scale ( 5 point scale: Always $=5$, Often $=4$, Occasionally $=3$, Rarely $=2$, and Never $=1$ ).

To facilitate judging the extent of Netiquette practices implementations (the Cutoff Score), the recorded Netiquette extents were classified into five categories based on the arbitrators' agreement. As a result, the Netiquette extent was considered never among the category of means (1-1.8), rarely among the category of $(1.8<-2.6)$, occasionally within the category $(2.6<-3.4)$, often within the category $(3.4<-4.2)$, and always among the category of means $(4.2<-5.00)$.

\subsection{Validity}

Questionnaire validity was verified by (10) arbitrators. The research instrument was distributed to a group of experts in education and psychology at several Jordanian universities. Arbitrators highlighted several comments and suggestions regarding wording, readability of items, and belonging to the main domain. The experts added, deleted, and modified what they see fit. Items of the questionnaire were modified based on opinions of the majority of the arbitrators. The final edited draft has consisted of (42) items.

\subsection{Reliability}

After distributing the research questionnaire to (22) students from outside the study sample and collecting the data, the reliability was ascertained by the splithalf method. All items of the questionnaire were divided randomly into two sets. The stability of reliability was calculated through Spearman-Brown Coefficient. The calculated value was (0.82). In addition, Internal Consistency Reliability was calculated through Cronbach's Alpha Coefficient which was $(0.85)$. These results guided the researchers to pursue conducting the study. 


\subsection{Statistical Treatment}

Researchers recorded all the participants' responses and used SPSS to analyze collected data. The Means and Standard Deviations were calculated to answer the first question. In addition, a one-way ANOVA test was conducted to answer second, third, and fourth questions.

\section{$9 \quad$ Results and Discussion}

The first research question is: To what extent do undergraduate students, at the Faculty of Educational Sciences at TTU practice Netiquette rules? To answer this question, Means and Standard Deviations were calculated. The total Means of the extents of implementing Netiquette practices among the participants was (2.8866) and Std. Deviation was (.20340). Since the total Means is cited within the category $(2.6<-$ 3.4 ), this indicates that, in general, the students are implementing Netiquettes' practices occasionally (3 on Likert Scale). That is, Jordanian undergraduate students are not familiar enough with Netiquette practices. This result meets with previous literature of Aranda [3] that stressed the importance of providing clear and general guidelines for proper Netiquette among students. In addition, Aggarwal [1], Kozík and Slivová [21], and Deepa and Ghatak [11] recommended organizing workshops and training sessions by academic institutions to help student be familiar with Netiquettes.

In addition, to respond to the research's first question the Means and Standard Deviations of the extent to which the participants practice Netiquette rules regarding each of items in the research instrument were calculated. The results show that the highest Mean was (4.40) and its Standard Deviation was (.726). It was given to the item that stated: "I don't post spelling or grammar flames". The following item's Mean was (3.97) and its Standard Deviation was (.797): "My posts reflect my point of view and not reflecting the words of others". The third highest item was: "It's not nice to hurt other people's feelings". This item's Mean was (3.89) and its Standard Deviation was (.856). The fourth highest item was: "I believe that breaking the law is bad Netiquette". Its Mean was (3.87) and its Standard Deviation was (.809). The four highest results indicate that the students have a consensus regarding the general rules of Netiquette. They mentioned that they respect others' feelings and do not send posts that may hurt others. In addition, they express their personal insights. However, the participants highlighted lower extent of practicing specific rules related to (do's and don'ts) for Netiquette. One of the mentioned rules was "I don't post subscribe, unsubscribe, or FAQ request that are not related to discussed topic". The Mean of the item was (3.02) and its Standard Deviation was (.873). The Mean of this item reflects that the participants are using this rule occasionally because the Mean is within the category $(2.6<-3.4)$.

On the other hand, reviewing the least frequently implemented practices of Netiquette among undergraduate students reveal the limited use of "standard language when communicating with others". The item's Mean was: (1.75) and its Standard Deviation was (.790). Furthermore, the students point out that they lack the skill of appropriate citation. The item that highlights this rule was: "I cite ideas and infor- 
mation (whether are words, pictures, or videos) used in my posts in discussion groups". The item's Mean was (1.63) and its Standard Deviation was (.894). Another low practice was reflected in the item: "Posts and comments that I do always have titles that reflect the content of the post". The item's Mean was (1.62) and its Standard Deviation was (.735). These items reflect the category Never (Means range between 1-1.8). Since participants reveal that they never use standard language and appropriate citation in their online communication, a clear effort should be invested to inform the students about the importance of the appropriate academic writing among university students when they utilize online communication tools. Disseminating the knowledge at university level can affect the quality of online communication among users especially when they represent higher education institutions. These results support Aggarwal [1] conclusion that users communicate via social media should be guided to follow and understand standards of electronic communication or Netiquette to keep each person civil and safe. Furthermore, individuals are entitled to behave themselves or to their own behaviors and free speech using and communicating via social media but with a responsibility.

When it comes to practicing critical thinking skills while utilizing Netiquette practices, the students' perspectives show limited extent of Netiquette practices related to critical thinking skills. One of related items: "When appropriate, I use private email instead of posting to the group" indicate limited awareness (Means of the item was (2.50) and its Standard Deviation was (1.213)). The Mean of this item reflects that the participants are using this rule rarely because its Mean is located among the category of $(1.8<-2.6)$. That is, the participants rarely choose the appropriate context to present their insights. Moreover, the following item pointed out the limited use of some critical thinking skills such as summarizing thoughts and insights. The item stated: "If I have received email answers to a posted question, I summarize them and post the summary to the discussion group". Mean of the item was (1.56) and its Standard Deviation was (.648). The Mean of this item reflects that the participants are never using this rule because it is located in the category of Means (1-1.8). As a result, summary skill is not practiced among the participants. Furthermore, the lowest implemented practice was represented in the item: "I read the FAQ (Frequently Asked Questions) document before posting". Mean of the item was (1.39) and its Standard Deviation was (.648). This result shows that the participants do not read and reflect carefully before posting new insights. Consequently, more attention should be given to the relationship between Netiquette rules and critical thinking skills. This relationship should be disseminated among university students to see higher extent of implementation of Netiquette rules and critical thinking skills than what was shown in this research results among Jordanian undergraduate students.

The second research question is: Are there statistically significant differences at the significance level of $(\alpha=0.05)$ between Means responses of undergraduate students regarding practicing Netiquette rules attributed to the students' gender? To answer the question, One Way ANOVA was calculated. Table 2 shows the results.

Table 2 indicates that there are no statistically significant differences in the students' perspectives regarding the extent of their implementation of Netiquette practices attributed to the gender variable. Specifically, the value of $F$ was (.067), which is 
not statistically significant at the level of significance $(\alpha=0.05)$. This result reveals that both male and female students at TTU have the same experiences in implementing Netiquette rules. This result could be related to etiquette rules that students use in face-to-face communication due to cultural context. Jordanian context is conservative. Therefore; this result is expected because online communication as well as face-toface communication reflects signs of families' socialization types. This result disagrees with the results of Bromseth's [6] study that point out Netiquette practices are linked to gender.

The third question is: Are there statistically significant differences at the significance level of $(\alpha=0.05)$ between Means responses of undergraduate students regarding practicing Netiquette rules attributed to the students' specialization?, and the fourth question in this research is: Are there statistically significant differences at the significance level of $(\alpha=0.05)$ between Means responses of undergraduate students regarding practicing Netiquette rules attributed to the students' university study level?

To answer these two questions Tables 3 and 4 point out the results of One Way ANOVA for the impact of specialization and university study level.

Table 3 and Table 4 reveal that there are no statistically significant differences in the participants' Netiquette practices that are attributed to any of the variables: specialization (the value of $F$ was (.241), which is not statistically significant at the level of significance $(\alpha=0.05)$, and university study level (the value of F was (.749), which is not statistically significant at the level of significance $(\alpha=0.05)$. That is, students'

Table 2. One Way ANOVA for the impact of Students' gender on their Netiquettes Practices

\begin{tabular}{|l|c|c|c|c|c|}
\hline & Sum of Squares & df & Mean Square & F & Sig. \\
\hline Between Groups & .003 & 1 & .003 & .067 & .796 \\
\hline Within Groups & 10.091 & 243 & .042 & & \\
\hline Total & 10.094 & 244 & & & \\
\hline
\end{tabular}

Table 3. One Way Anova For The Impact Of Students' Specialization On Their Netiquettes Practices

\begin{tabular}{|l|c|c|c|c|c|}
\hline & Sum of Squares & df & Mean Square & F & Sig. \\
\hline Between Groups & .010 & 1 & .010 & .241 & .624 \\
\hline Within Groups & 10.084 & 243 & .041 & & \\
\hline Total & 10.094 & 244 & & & \\
\hline
\end{tabular}

** Statistically significant at the level of significance $(\alpha=0.05)$

Table 4. One Way Anova For The Impact Of Students' University Study Level On Their Netiquettes Practices

\begin{tabular}{|l|c|c|c|c|c|}
\hline & Sum of Squares & df & Mean Square & F & Sig. \\
\hline Between Groups & .031 & 1 & .031 & .749 & .388 \\
\hline Within Groups & 10.063 & 243 & .041 & & \\
\hline Total & 10.094 & 244 & & & \\
\hline
\end{tabular}

** Statistically significant at the level of significance $(\alpha=0.05)$ 
perspectives of the extent of their implemented Netiquette practices did not affect by their specialization and university study level. These results indicate that students from third year and fourth year of their study journey show no difference in their perspectives regarding Netiquette implemented practices. In addition, participants from different specializations have common practices when they deal with Netiquette rules and ethics. The reason could be related to the first finding in this research about the limited knowledge of the concept of Netiquette and its practices. The other expected reason of these results is that Netiquette practices are related to the personal attributes and habits more than content knowledge that may be affected by specialization and study level.

\section{Conclusion and Future Recommendation}

Currently, Netiquette practices are playing a vital role in enhancing the level of effective online communication. As a result, this study attempted to highlight students' perspectives of the extent of their implemented Netiquette practices. The main findings showed that the participants have limited level of awareness of the Netiquette concept and its practices. In addition, students' perspectives of Netiquette practices varied. It is obvious that students do not give adequate attention to the appropriate use of standard language when communicating with others. In addition, they lack the skill of appropriate citation when they present their insights. The results focused on the importance of preparing students of 21 st century to be familiar with the Netiquette rules. Further, it is crucial for institutions of higher education to incorporate the Netiquette ethics of computer-mediated communication (CMC) in their study programs. As a result, future seminars, trainings, and workshops are recommended to help university students recognize all of the aspects of Netiquettes and implement them. Reviewing the study findings can help educational stakeholders to disseminate Netiquette concept and its rules among undergraduate students. Further studies that investigate the impact of Netiquettes on other users are recommended.

\section{References}

[1] Aggarwal, A. K. (2014). Netiquette in e-learning. Proceedings for the Northeast Region Decision Sciences Institute (NEDSI), 181-182.

[2] Agnew, D. S., \& Hill, K. (2009). Email etiquette recommendation for today's business student. Allied Academies International Conference: Proceedings of The Academy of Organizational Culture, Communications \& Conflict (AOCCC), 14(2), 1-5.

[3] Aranda, J. F. (2007). Netiquette and online communication. Journal of Instruction Delivery Systems, 21(4), 11-14.

[4] Biesenbach-Lucas, S. (2007). Students writing emails to faculty: An examination of epoliteness among native and non-native speakers of English. Language Learning and Technology, 11(2), 59-81.

[5] Boicu, R. (2011). Discursive norms in blogging. Romanian Journal of Journalism \& Communication / Revista Romana De Jurnalism Si Comunicare- RRJC, 6(1), 54-62. 
Paper-Undergraduate Students' Perspectives of the Extent of Practicing Netiquettes in a Jordanian Sou...

[6] Bromseth, J. H. (2001). Constructions of and negotiations on interaction norms and gender on electronic discussion lists in Norway. NORA: Nordic Journal of Women's Studies, 9(2), 80-88. https://doi.org/10.1080/080387401753355308

[7] Brusco, J. M. (2011). Know your netiquette. AORN Journal, 94(3), 279-286 8p. https://doi.org/10.1016/j.aorn.2011.07.003

[8] Buelens, H., Totté, N., Deketelaere, A., \& Dierickx, K. (2007). Electronic discussion forums in medical ethics education: the impact of didactic guidelines and Netiquette. Medical Education, 41(7), 711-717. https://doi.org/10.1111/j.1365-2923.2007.02793.x

[9] Canada, M. (2000). Students as seekers in online courses. In R. E. Weiss, D. S. Knowlton, \& B. W. Speck (Eds.), Principles of effective teaching in the online classroom, 75(84), 3540. Francisco: Jossey- Bass https://doi.org/10.1002/t1.845

[10] De Cindio, F., Gentile, O., Grew, P., \& Redolfi, D. (2003). Community networks: Rules of behavior and social structure special issue. ICTs and community networking, 19(5), 395406.

[11] Deepa, S., \& Ghatak, S. (2013). Netiquette: Exploratory study of actual usage and agreed upon norms in India. Scholars world-irmjcr, 1(3), 129-136.

[12] Farshad Nia, S., \& Marandi, S. (2014). Digital literacy and Netiquette: Awareness and perception in EFL learning context. In S. Jager, L. Bradley, E. J. Meima, \& S. Thouësny (Eds), CALL Design: Principles and Practice; Proceedings of the 2014 EUROCALL Conference, Groningen, The Netherlands (pp. 77-82). Dublin: Research-publishing.net. https://doi.org/10.14705/rpnet.2014.000198

[13] Flynn, N. (2009). Chapter 10: Netiquette Rules. In e-Policy Handbook: Rules \& Best Practices to Safely Manage Your Company's E-Mail, Blogs, Social Networking, \& Other Internet Communication Tools (pp. 85-90). American Management Association International.

[14] Glass, G. V., \& Hopkins, K. D. (1984). Statistical Methods in Education and Psychology ( $2^{\text {nd }}$ ed.). Englewood Cliffs, N. J.: Prentice-Hall.

[15] Hardy, J. (2012). Netiquette: It's a job skill. Business in Calgary, 22(9), 26-31.

[16] Hawkes, M. (2006). Linguistic discourse variables as indicators of reflective online interaction. American Journal of Distance Education, 20(4), 231-244. https://doi.org/10.1207/s15389286ajde2004 4

[17] Hills, L. (2011). E-mail Netiquette for the medical practice employee: 50 do's and don'ts. Journal of Medical Practice Management, 27(2), 112-117.

[18] Hodges, J. G. (2010). Social networking rules of etiquette. Journal of Practical Estate Planning, 12(3), 9-58.

[19] Johnson, D. (1999). Handout for teaching students right from wrong in the digital age. Retrieved on May 7, 2016 from: http://www.janinelim.com/bc/4thur/ethics.pdf

[20] Jong, T.M. de, van der Voordt, D.J.M. (2002). Ways to study architectural, urban and technical design. Delft: DUP Science, 53-60.

[21] Kozík, T., \& Slivová, J. (2014). Netiquette in electronic communication. International Journal of Engineering Pedagogy, 4(3), 67-70. https://doi.org/10.3991/ijep.v4i3.3570

[22] Kryder, C. (2013). Online etiquette in the digital age. American Medical Writers Association Journal, (3), 130.

[23] Liu, X., Magjuka, R. J., Bonk, C. J., \& Lee, S. (2007). Does sense of community matter? An examination of participants' perceptions of building learning communities in online courses. Quarterly Review of Distance Education, 8(1), 9-24.

[24] Loguercio, M. (2012). Social etiquette. Insurance Advocate, (5), 8. 
Paper-Undergraduate Students' Perspectives of the Extent of Practicing Netiquettes in a Jordanian Sou...

[25] Mahar, S. M., \& Mahar, J. (2009). Chapter 6: Netiquette and codes of conduct. In Unofficial Guide to Building Your Business in the Second Life Virtual World (pp. 102-113). American Management Association International.

[26] Marcoccia, M. (2012). The Internet, intercultural communication and cultural variation. Language and Intercultural Communication, 12(4), 353-368. https://doi.org/10.1080/ $\underline{14708477.2012 .722101}$

[27] Merriam-Webster's Learning Dictionary (2016). Etiquette. Retrieved on May 7, 2016 from: http://www.learnersdictionary.com/search/etiquette

[28] Merriam-Webster's Learning Dictionary (2016). Internet. Retrieved on May 7, 2016 from: http://www.learnersdictionary.com/definition/Internet $\% 20$

[29] Neurauter-Kessels, M. (2011). Im/polite reader responses on British online news sites. Journal of Politeness Research: Language, Behavior, Culture, 7(2), 187-214. https://doi.org/10.1515/jplr.2011.010

[30] Palloff, R. M., \& Pratt, K. (2001). Lessons from the cyberspace classroom: The realities of online teaching. San Francisco: Jossey-Bass.

[31] Preece, J. (2004). Etiquette online: From nice to necessary. Communications of the ACM, 47(4), 56-61. https://doi.org/10.1145/975817.975845

[32] Scheuermann, L. \& Taylor, G. (1997). "Netiquette". Internet Research: Electronic Networking Applications and Policy, 7(4), 269-273. https://doi.org/10.1108/106622 49710187268

[33] Shea, V. (1997). Netiquette. Retrieved on May 7, 2016 from: http://www.albion.com/ Netiquette/book/index.html

[34] Stewart, G. (2014). Reviewing and ethics in the online academy. Educational Philosophy and Theory, 1-6. https://doi.org/10.1080/00131857.2014.950804

[35] Watkins, C. (2005). Classrooms as learning communities: A review of research. London Review of Education, 3(1), 47-64. https://doi.org/10.1080/14748460500036276

[36] West, R. (2010). A student's guide to strengthening an online community. TechTrends: Linking Research \& Practice to Improve Learning, 54(5), 69-75. https://doi.org/10.1007/ s11528-010-0439-7

[37] Yarmohammadian, M. H., Iravani, H., \& Abzari, M. (2012). Information and communications technology, culture, and medical universities; organizational culture and Netiquette among academic staff. Journal of Education and Health Promotion, 1, 1-6. https://doi.org/10.4103/2277-9531.94414

\section{Authors}

Y.M. Arouri is an Assistant Professor - Department of Curriculum and Instruction at Tafila Technical University, Jordan. Email: arouri@ttu.edu.jo

D.H. Hamaidi is an Associate Professor - Department of Curriculum and Instruction at The University of Jordan, Jordan. Email: dhamaidi@ju.edu.jo

Article submitted 19 November 2016. Published as resubmitted by the authors 23 January 2017. 